\title{
CLINICAL TRIAL FACTORS IN A PAIN TRANSITION STATE MODEL
}

\author{
Meyer Katzper \\ Center for Drug Evaluation and Research \\ Food and Drug Administration \\ Rockville, MD 20857, U.S.A.
}

\begin{abstract}
This paper presents a pain state transition model which accounts for constraints used in clinical trials. The pain transition state model is an approach for summarizing, presenting and modeling pain state transitions in a population. Data used are from the ibuprofen arm of a number of clinical trials measuring dental extraction pain. The data determine the state transition coefficients of the model. The pain process in the presence of an analgesic is thus fully characterized.
\end{abstract}

\section{INTRODUCTION}

Patients and physicians are interested in knowing the likelihood of relief, the time of onset of relief, the degree of relief and the persistence of relief when an analgesic is taken. There is not a unique answer to such inquiries. The answer can only be given in probabilistic terms. Even the question whether the patient will obtain relief can only be answered in probabilistic terms. The time to relief is uncertain. The degree of relief is uncertain. The relief may or may not persist. The answer to these questions constitutes an analgesic's profile. Individuals have different profiles with respect to an analgesic. The analgesic itself has a statistical profile with respect to a given population. It is this profile which we can establish using clinical trials. In deciding among different analgesics their profiles can be compared to determine which one to choose. This paper uses data from a single analgesic, ibuprofen, in conjunction with a model to characterize the dynamic pain transitions of the population. The underlying goal is to determine characteristic transition coefficients for each analgesic of interest. Based on an earlier model (Katzper 2005) this revised model accounts for constraints used in clinical trials. It matches the ibuprofen data very well. This fit demonstrates that the methodology can be applied to any analgesic. Transition coefficients fitted to various analgesics could be used to compare the relative efficacy of the analgesics.

\section{BACKGROUND}

A biological model used for determining the efficacy of analgesics in acute pain is the dental pain model. In the dental pain model 3rd molars, commonly know as wisdom teeth, are extracted. Subsequently, the patent is given either a test analgesic or a placebo or a known analgesic. The patient is then asked at fixed intervals of time how much pain they have. Results are compared among the groups getting the test analgesic, the placebo and the known analgesic. This methodology has been used by the Food and Drug Administration (FDA) to determine the efficacy of new analgesics.

Measurement of pain uses either a Visual Analog Scale (VAS) or a categorical scale. A standard categorical scale has the categories no pain. mild pain, moderate pain, severe pain. Categorical measures lend themselves to compartmental modeling. The compartments are taken as the categorical states and the transition between states is the exchange between compartments. The use of such a pain transition model can capture the desired population measures. Such an approach for modeling pain alleviation has been used in the past (Katzper 1997, Katzper 2005). This paper is a revision of past work to better account for clinical trial factors.

\section{CONSIDERATIONS}

There is an option of remedication for patients who are in pain and not getting relief. Once patients remedicate their state no longer gives information relevant to the trial. Therefore, patients are strongly urged not to remedicate at least for the first hour after getting their medication. Accounting for this factor is the major revision which has been made to the prior model. Other relevant considerations are discussed in the previous paper (Katzper 2005). Our approach accounts both for the relief of those remaining in the trial without re-medication and the number of those re-medicating.

Note that in earlier studies I looked at the pharmacokinetic (PK) and pharmacodynamic (PD) data and modeled 
the pain alleviation process for individuals and for group means (Harter and Katzper 1993, Harter and Katzper 1994, Harter and Katzper 1995). This study models the transitions of a population between pain states by using the number of subjects in each category of pain as the entity tracked under the given clinical conditions of the dental pain model. This tracking of pain states versus time gives a summary of expected results and directly answers questions of interest (Katzper 1997).

\section{DETAILS OF THE DATA}

For use with this model dental molar extraction control arms from 10 studies that used Ibuprofen $400 \mathrm{mg}$ as the comparator have been combined. Pain states are recorded categorically as $0,1,2,3$ or remedicated. This standard measure of pain is the four point pain intensity category scale shown in Table 1 (Max, Portenoy, and Laska 1991). The analysis here uses the remedicated state as a valid categorical state in addition to the standard pain states.

Table 1. Categorical Pain Values

\begin{tabular}{|c|c|}
\hline Pain State & Assigned Value \\
\hline Severe & 3 \\
\hline Moderate & 2 \\
\hline Mild & 1 \\
\hline None & 0 \\
\hline
\end{tabular}

Only subjects with severe or moderate pain are allowed in the clinical trial. This is the clinical protocol. This is so for all data used.

After molar extraction, 400 milligrams of ibuprofen were given to all 492 subjects assembled in this data set. For the combined data set 34 percent start in severe pain (Pain State 3) and 66 percent start in moderate pain (Pain State 2).

Pain state data are available for times $1 / 2$ hour, 1 hour, 1 $1 / 2$ hours, 2 hours, 3 hours, 4 hours, 5 hours and 6 hours. The number of subjects in each state at each time was counted for a summarization of the data. The results for those that started with severe pain are given in Figure 1. Graphing the numbers in each state versus time gives a picture of the effectiveness of the medication over the time period that the data was collected. The pain graph is presented normalized to 100 percent for the entirety of the severe pain population. The shape is not affected by this transformation. Percentages can be read directly from the graph. This format is desirable for comparison with other drugs.

As expected, over time the number with severe pain decreases and those with moderate, mild or no pain initially increases. Remedicators increase after one hour be-

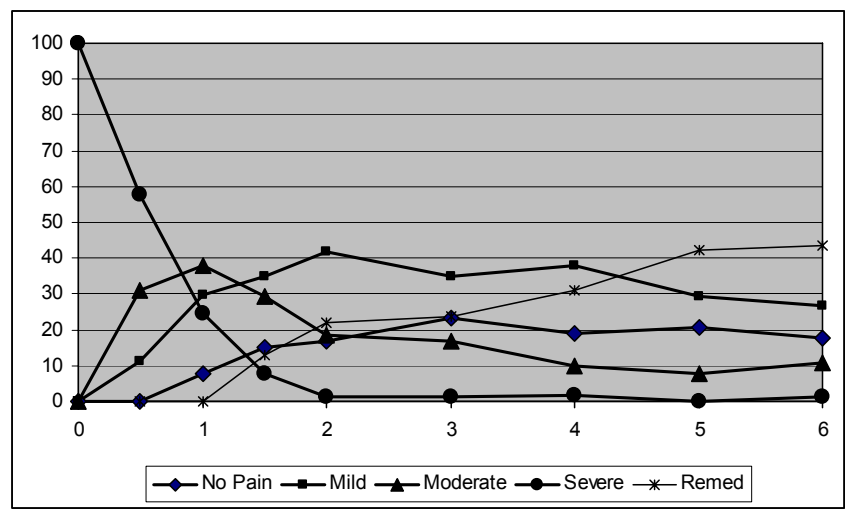

Figure 1. Percent Initially Severe Pain Subjects In Pain States Over Time

cause they are constrained from remedicating until one hour. Remedication is an absorbing state, which can only increase.

An excellent intuitive representation of the progress of the population over time is depicted in the following alternative representation. Such a graph presents a superior overview. Each state can be easily followed over time. We see the decline in the portion of subjects with severe pain concomitantly with the rise in population in the other states.

This representation summarizes the pain history of the entire population starting with severe pain. A similar representation may be given for those starting with moderate pain. As in any summarizing, there is a loss of individual information.

Another way of representing this data is by showing percentages of pain state occupancy at each time. Figure 2 shows the progression for subjects initially in severe pain (pain state 3). It is this representation of the data that the model seeks to capture. The model can then be used for comparative purposes or to simulate the effects of a drug with modified transition coefficients.

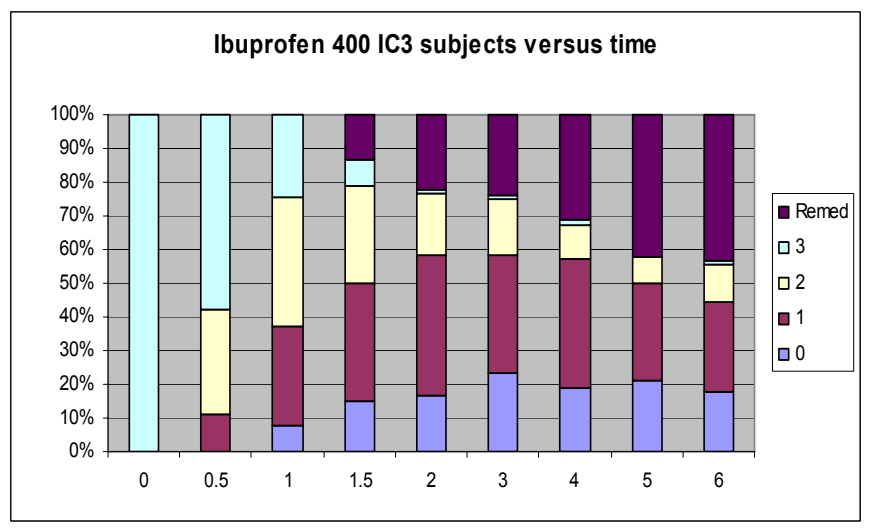

Figure 2. Progression For Subjects Initially In Severe Pain To All Pain States At All Recorded Times. 


\section{MODELING PAIN TRANSITIONS}

The different dynamics of the initial severe pain states and initial moderate pain states leads us to model and estimate the transition coefficients for the two states separately. The model we formulate is identical in both cases. The initial model is shown in Figure 3. The rectangular boxes are the pain states.

The Tij are the transition between states. As most transitions are bi-directional, the Tij are composed of aij and aji transition coefficients, one for each direction. Specifically we have:

- $\quad \mathrm{a} 01=$ from no pain to mild

- $\quad \mathrm{a} 10=$ from mild to no pain

- $\quad \mathrm{a} 12=$ from mild to moderate pain

- $\quad \mathrm{a} 21=$ from moderate to mild pain

- $\quad \mathrm{a} 23=$ from moderate to severe pain

- $\quad \mathrm{a} 2 \mathrm{R}=$ from moderate pain to remedication

- $\quad \mathrm{a} 32$ = from severe pain to moderate pain

- $\quad \mathrm{a} 3 \mathrm{R}=$ from severe pain to remedication

The model was formulated in STELLA ${ }^{\mathrm{TM}}$ (Hannon and Ruth 1994). It was transformed into MADONNATM (Hannon and Ruth 1994), where a fit for all the transition coefficients was obtained.

A sample fit for one of the pain states is shown in Figure 4. It shows data and model fit for the population starting with initial severe pain and transitioning to moderate pain. All the other curves were similarly fit and all the transition coefficients determined.

Looking at the data and the results of the model the large degree of correspondence between data and fit to the data by the model is evident. However, upon close inspection it seemed that the transition coefficients for the first hour might differ from the subsequent time transition coefficients. The model was not designed to deal with this contingency. An alternative hypothesis is that the model could retain the same transition coefficients over time, but the special conditions of the first hour have to be taken into account. This is the approach that is presented in this paper. The revised model allows for a pent up demand for remedication which becomes active starting at one hour. The initial model is shown in Figure 3 and the revised model is shown in Figure 5.

The revised model necessitates transition constants for the pent up but not expressed demand for remedication. The remedication data and model fit are shown in Figure 6. Clearly, the fit does not capture the subtleties of the data.

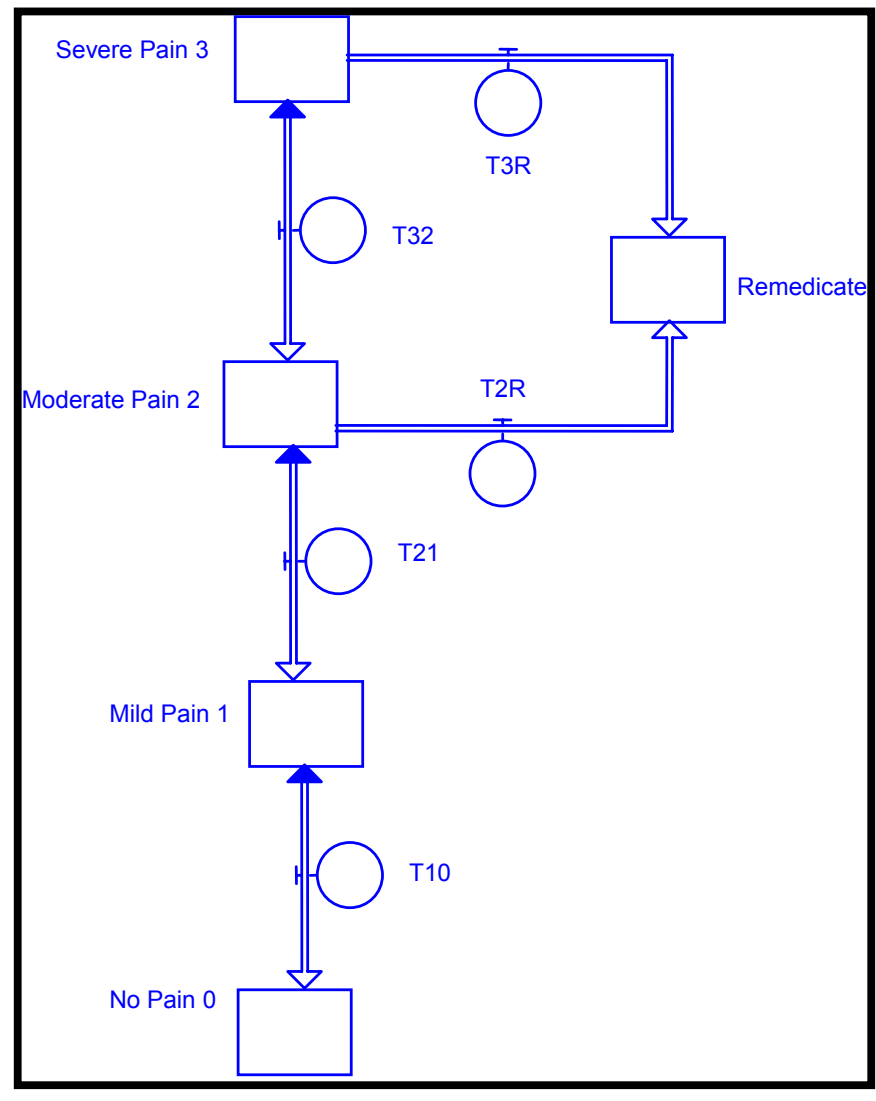

Figure 3. Pain State Model STELLA ${ }^{\mathrm{TM}}$ Representation

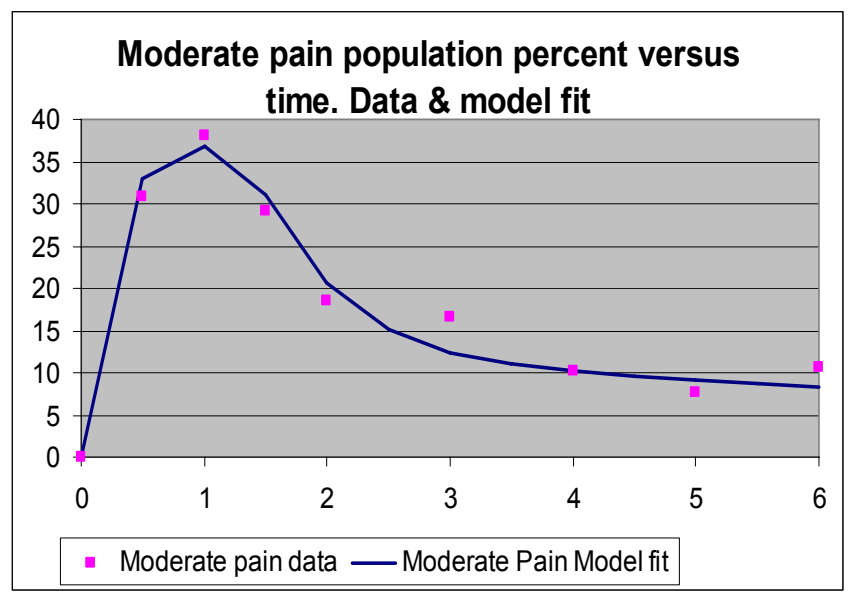

Figure 4. Moderate Pain State Percent Occupation 


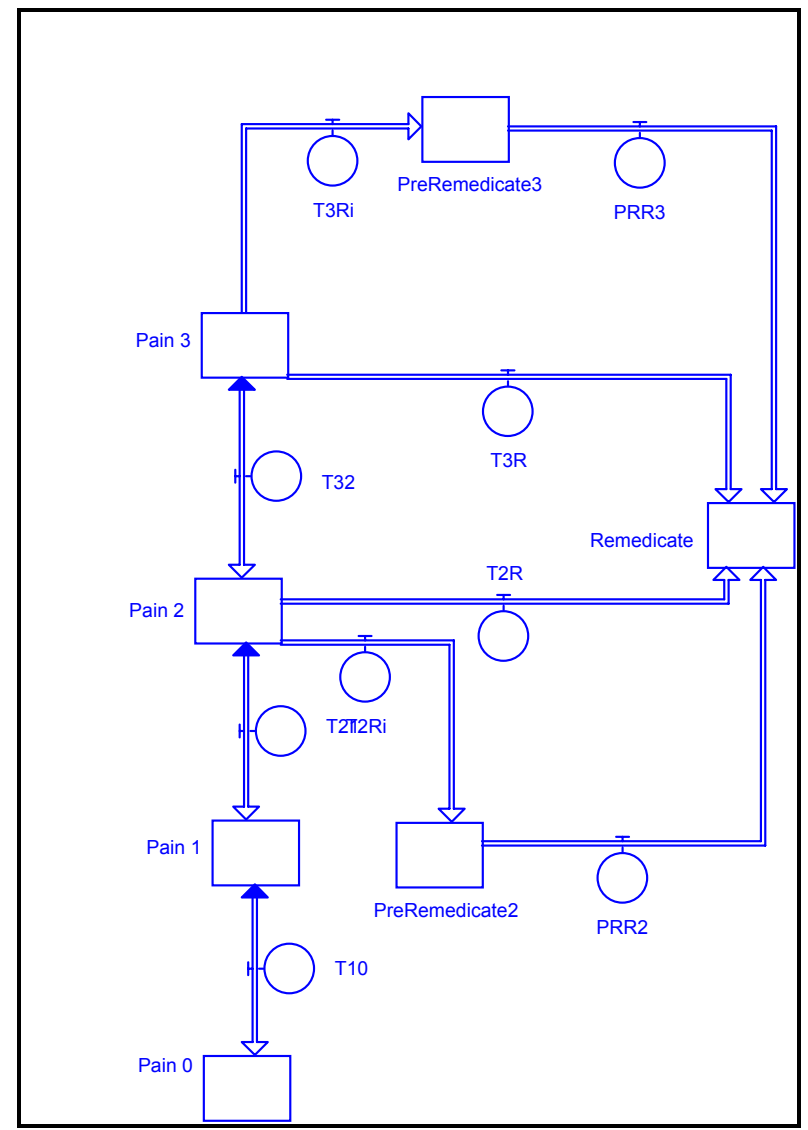

Figure 5. Revised Pain State Model Representation.

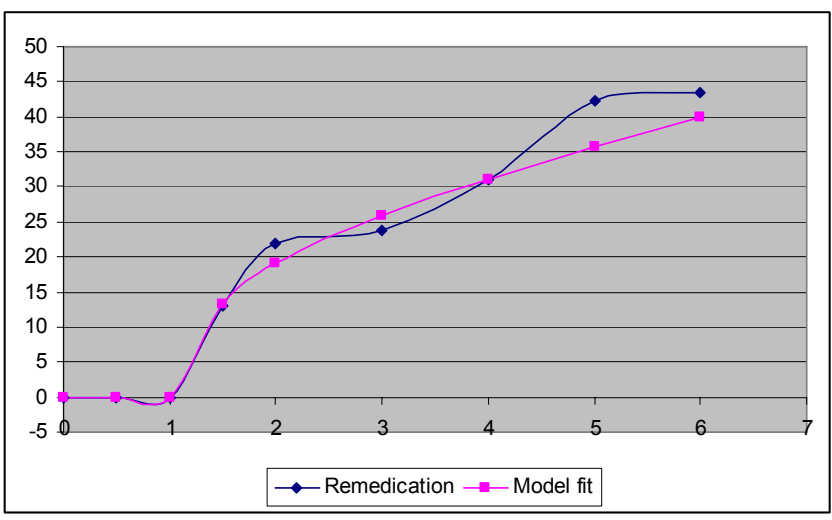

Figure 6. Remedication State Percent Occupation

\section{CONCLUSION}

The pain state model allows one to simulate the outcome of varying transition rates. However, the remedication example, where the model generally reproduces the data but shows definite deviations from the data, demonstrates that the variability in human response can only crudely be captured by our conceptual constructs. Nevertheless our simulation results can show what expectations we can be have with regard to our analgesics.

\section{REFERENCES}

Hannon, B. M. and Ruth M. 1994. Dynamic modeling. London : Springer-Verlag

Hannon, B. M. and Ruth M. 1997. Modeling dynamic biological systems. New York: Springer-Verlag

Harter J. and M. Katzper. 1993. Modeling pain and its response to analgesics. Clinical Pharmacology and Therapeutics, 53 No. 2. (February):171.

Harter J. and M. Katzper. 1994. Refinements in modeling pain and its response to analgesics, Clinical Pharmacology and Therapeutics. 55 No. 2, (February): 123.

Harter J. and M. Katzper. 1995. Components of pain alleviation. Western Simulation Multiconference: Health Sciences, Physiological and Pharmacological Simulation Studies.

Katzper M. 1997. Pain alleviation modeling by response levels. Simulation in the Medical Sciences. Proceedings of the 1997 Western Simulation Multiconference.

Katzper M. 2005. Pain state modeling. Health Science Simulation. 2005 Western Simulation Multiconference.

Max, M.B., R.K. Portenoy and E.M.Laska 1991. Advances in pain research and therapy: The design of analgesic clinical trials. Raven Press, N.Y.

\section{DISCLAIMER}

The opinions expressed in this paper are the professional views of the author and do not necessarily reflect the official position of the U.S. Food and Drug Administration.

\section{AUTHOR BIOGRAPHY}

MEYER KATZPER is an analyst and modeler for the Food and Drug Administration. He carries out modeling, simulation and data analysis to enhance the drug review process. He creates and uses pharmacokinetic, pharmacodynamic and physiologically oriented models in the analysis of drug data. The goal, wherever possible, is to foster a mechanistic based understanding of pharmacological effects in order to better assess the safety and efficacy of drugs. His e-mail address is katzper@cder.fda.gov 